\title{
Foreign language teachers' language proficiency and their language teaching practice
}

\author{
Heather Richards, Clare Conway, Annelies Roskvist and Sharon Harvey \\ School of Language and Culture, Auckland University of Technology, Auckland, New \\ Zealand
}

Corresponding author:

Heather Richards, Auckland University of Technology, Private Bag 92006, Wellesley Street,

Auckland 1142, New Zealand

+6499219999 x6046

Heather.richards@aut.ac.nz

\section{Biographical notes on contributors}

\section{Heather Richards}

Heather Richards is a Senior Lecturer in the School of Language and Culture in the Faculty of Culture and Society at AUT University. Heather is an experienced language teacher educator who has worked in both the private and public sector. Her research interests are in learning transfer, teachers' and learners' perceptions of learning gains, and developing learner intercultural competence.

\section{Clare Conway}

Clare Conway is a Senior Lecturer in the School of Language and Culture in the Faculty of Culture and Society at AUT University. She is the programme coordinator of the Master of Professional Language Studies in Language Teaching. Her research interests include linking theory and practice in intercultural language teaching, reflective practice and learning through multi-media.

\section{Annelies Roskvist}

Annelies Roskvist is the Associate Head of the School of Language and Culture. She has research interests in several areas related to language and language teaching and her current research interests include immersion/study abroad programmes for teachers of languages, and the teaching of intercultural competence.

\section{Dr Sharon Harvey}


Dr Sharon Harvey is Head of the School of Language and Culture and Deputy Dean (Research and Postgraduate) in the Faculty of Culture and Society at AUT University. Sharon researches, publishes and supervises in the areas of higher education policy, language teacher development, intercultural competence, discourse analysis and critical language studies. 


\section{Foreign language teachers' language proficiency and their language}

\section{teaching practice}

Teachers' subject knowledge is recognised as an essential component of effective teaching (Gibbs and Holt, 2003; MOE 2007; Pachler, 2007; Murdoch, 1994; Shin, 2008). In the foreign language context, teachers' subject knowledge includes language proficiency. In New Zealand high schools foreign language learning has long been part of the curriculum. However, recently foreign languages (eg. Chinese, French, German, Japanese and Spanish) have been offered to learners earlier in their schooling, prompting a demand for more foreign language teachers. A nation-wide professional development programme for language teachers is building language teacher capacity to meet the demand. Participants on the programme have a range of language teaching subject knowledge. While some have extensive knowledge of their target teaching language but lack formal language teaching qualifications, others are generalist teachers with an interest in teaching a foreign language who are just beginning to develop their subject knowledge. This paper considers teachers' subject knowledge, i.e. their language proficiency. We report on the differences in the classroom practice of teachers with limited subject knowledge, compared with teachers with more extensive subject knowledge. The data were analysed against key aspects of teaching based on the work of Farrell and Richards (2007). The analysis revealed a variance in the number of key aspects the teachers could manage and differences in their level of effectiveness in managing the key aspects. We highlight the importance for teachers with limited levels of target language proficiency to continue developing their subject knowledge in order to maximise the language learning experience for their students.

Key words: subject knowledge; teacher language proficiency; foreign language; modern language; classroom practice

\section{Introduction}

The New Zealand Ministry of Education is committed to students completing their schooling with the ability to meet the challenges of a multicultural environment both in New Zealand and beyond (Ministry of Education, 2007). Knowing more than one language enables people from different cultures to communicate, as well as to come to a greater understanding of their own world. Learning foreign languages (known as the learning of 'additional languages' in New Zealand) has long been part of the curriculum in New Zealand English-medium high schools for learners aged 13-17. However, from 2010, schools have been expected to offer a foreign language to students earlier on in their schooling, that is to learners aged 11-12. This new expectation has prompted a need for more foreign language teachers. The task of finding and retaining sufficient numbers of qualified foreign language teachers has posed a challenge (Guthrie, 2005:45; East 2007:7; Education Review Office, 2009) which is not dissimilar to situations in other countries, such as Scotland (Crichton \& Templeton 2010:141) and Turkey (Stelma \& Onat-Stelma 2010:193). 
One response to the challenge in New Zealand is a one year, part-time professional development programme to build language teacher capacity - the Teacher Professional Development Languages (TPDL) programme. TPDL has three components to develop teachers' subject knowledge. In the Language Study component teachers develop their knowledge of and proficiency in their target teaching language (TL). In the Second Language Acquisition component teachers deepen their knowledge of how languages are learned and develop related classroom pedagogy for teaching language and culture based on the Learning Languages area of the New Zealand Curriculum (2007). The third component, In-School Support, gives teachers the opportunity to apply their developing knowledge of language, culture and teaching pedagogy in the classroom.

TPDL is offered to qualified teachers who are already teaching a language, but who lack formal language teaching instruction. As well it is offered to generalist teachers with a keen interest in learning how to teach a foreign language. While some of the teachers may hold a degree in the language they teach and have extensive knowledge, others are only beginning to develop their knowledge of the target teaching language. This raises the question of how someone can teach a language when they have limited knowledge and proficiency. It also raises the question on how variation in teachers' language proficiency may influence language teaching classroom practice. Our paper thus considers foreign language teachers' language proficiency and their language teaching practices. We explore the literature in the area of teacher subject knowledge before giving some background to the study and an overview of the data gathering and analysis undertaken. We present the results of the analysis, elaborate on the results in the discussion section and conclude by examining implications for building foreign language teacher capacity.

\section{Literature}

Literature in the area of subject knowledge stresses its importance for teachers. Subject knowledge "is the basis of a teacher's professional experience" (Pachler 2007:10) and an essential component of effective teaching (Ministry of Education, n.d). It is only when teachers have an extensive knowledge of subject matter that they are able to represent and formulate their knowledge so that it can be easily understood by learners (McNamara 1991:121). In the language teaching environment, Tsui (2003:54), when talking about English language teachers, states that teachers who have greater subject knowledge are able to present concepts in a range of ways, help learners make connections between concepts and give learners practice in meaningful dialogues.

For the foreign language teacher, subject knowledge has a number of components. These include knowledge of second language acquisition theory, pedagogical knowledge, curricular and syllabus knowledge, cultural knowledge, as well as teachers' proficiency in the target language and an awareness of the structure and features of the target language. (Pachelor, 2007). Pre-service courses for the foreign language teacher typically focus on developing teacher knowledge and skills in how and what to teach, as well as fostering an understanding of the theories that inform practice. Courses for teachers in schools also 
familiarise teachers with the curriculum, and with assessment requirements and standards. Depending on entry requirements, courses may or may not include a focus on two other key aspects of teachers' subject knowledge: language awareness and language proficiency. 'Language awareness' refers to knowledge of underlying language systems such as syntax, morphology, semantics, and phonology. 'Language proficiency', as defined by Bachman (1990:16), is 'knowledge competence or ability in the use of a language'. So the foreign language teacher needs to have an understanding of language systems and be able to use the language for communicative purposes in different situations. 'Having an excellent command of the target language is indeed one of the most important characteristics of outstanding foreign language teachers' (Shin, 2008:59) and for the non-native teacher 'language proficiency will always represent the bedrock of their professional confidence' (Murdoch, 1994:254). The first standard for the formal preparation of foreign language teachers in USA states that teachers should have a high level of language proficiency, understand how the target language is organised, and be able to make comparisons between the varieties of the target language as well as between the target language and other languages (ACTFL 2002:6). It also states that teachers need to show they are continuing to develop their knowledge in these three areas independently, beyond formal language teacher education. Ongoing language development by teachers is also encouraged by others (see for example, Borg 2001:28; Shin, 2008:62).

Teachers' subject knowledge has a direct impact on what takes place in the classroom. It is not only a key determinant in the quality of student foreign language learning (Gibbs and Holt 2003:27), but also essential for the teacher in managing many key aspects of classroom practice. Farrell and Richards (2007:57) suggest that teachers' limited English language proficiency is likely to influence a number of areas of their teaching practice.

One significant area is teachers' ability to access target language resources. Knowledge of subject is important for teachers to be able to effectively adapt or supplement the course book, evaluate the usefulness of the resources (McNamara 1991:116) and make use of authentic materials (Farrell \& Richards 2007:57) which will prepare and motivate learners to use language outside the classroom (Lightbown and Spada, 1999). Tsui (2003:54) notes that teachers with less subject knowledge tend to be more prescriptive, closely following text books. In contrast, those with more subject knowledge are able to reject unsuitable aspects of the textbook and offer alternative activities for development and practice.

Effective TL modelling is another area that requires good subject knowledge. An essential characteristic of the effective language teacher is language proficiency for accurate modelling of TL structure, lexis and pronunciation for learners (Nasserdeen 2001:22). Edge and Garton (2009:10), when describing roles the teacher has in the classroom, note that when modelling the TL teachers need to also give information about the language and how it is used. 
Subject knowledge also plays an integral part in providing corrective feedback. As Tsui comments, teachers with a greater degree of subject knowledge are 'more likely to detect students' preconceptions and correct them, [and] to deal with students' difficulties...[while] less knowledgeable teachers may reinforce misconceptions, incorrectly criticise students' correct answers and accept erroneous results' (2003:54). Lack of language proficiency may not only cause teachers to provide incorrect responses, but may influence teachers' ability to even distinguish learner errors in language use (Farrell and Richards 2007:57).

The teacher with deep knowledge of the TL language is also able to provide accurate explanations that are meaningful to learners. The most useful type of explanation is 'brief hints, guidelines and corrections', rather than complex, lengthy explanations (Scrivener, 2005:19). The skilled language teacher synthesises their knowledge to provide valuable prompts to help learners understand the usage of new structures and vocabulary.

Using the TL to organise students in class is essential in communicative language teaching which, by definition, involves teachers managing learners into pairs and groups for interactive activities. The teacher who uses the TL to organise and manage students provides them with opportunities to hear and respond to meaningful language in context. Farrell and Richards (2007:56) suggest that this oral based methodology may be difficult for foreign language teachers who have low level language proficiency, as they may be so pre-occupied with their own language difficulties that they cannot 'loosen their grip' over the class. Tsui (2003:54) notes that teachers with limited subject knowledge tend to 'emphasize seat work assignments and routinized student input' resulting in lack of genuine interaction using the TL.

The language teacher with good subject knowledge is able to draw on both their language awareness and language proficiency to provide extensive input for learners, which, as Ellis (2005:38) states, is a key principle for successful instructed language learning. To progress, language learners need exposure to comprehensible input, i.e. input +1 - language at the next level of development (Krashen, 1982). Teachers, a key source of input (Kim \& Elder, 2008:167), need to have a high level of proficiency in the TL so they use it confidently and accurately with their learners in the communicative classroom (Schulz, 1999:35). Teachers with advanced language proficiency also display flexibility, allowing them to adjust their language according to their learners' language proficiency. Chaudron (1998:64), reviewing research into teachers' language use in the second language classroom, reports that teachers are able to adapt their language according to the competence of their learners, making use of longer utterances to extend their advanced learners. Thus, teachers' use of the target language in classrooms 'almost....certainly plays a crucial part in determining the success (or otherwise) of classroom second language (L2) learning’ (Kim \& Elder 2008:167).

Teachers' language awareness and facility in the target language helps teachers to improvise, seizing the teaching moment and responding to students' immediate needs to enhance learning and make it memorable. Tsui notes that language teachers with greater 
subject knowledge are able to 'exploit opportunities for useful digressions' (2003:54). However, those teachers with limited subject knowledge may become more didactic or alternatively not teach aspects of the subject (McNamara 1991:115; Tsui, 2003:54). Borg (2001:26) describes a case study English language teacher with weak language awareness who, because he felt he lacked sufficient knowledge to answer students' questions, avoided the teaching of grammar.

To summarise the above, drawn largely from literature on English language teaching, subject knowledge can influence a number of aspects of teaching, and advanced subject knowledge is needed to provide maximum learning opportunities for students. However, in spite of the desirability of extensive subject knowledge, the reality is that in the New Zealand foreign language teaching context, there is a range of knowledge amongst teachers. While there are qualified language teachers in high schools who hold a degree in a foreign language, there are also teachers with less subject knowledge who are teaching languages at intermediate level schools. The purpose of this paper is to explore the link between foreign language teachers' subject knowledge and their language teaching classroom practice. It seeks to answer the question: What is the extent of the difference in the classroom practices of teachers with limited subject knowledge compared with teachers with more extensive subject knowledge?

\section{The study}

This paper draws on data from a larger study reported on in Harvey, Conway, Richards and Roskvist (2009) which evaluated the 2008 part-time TPDL programme in which 58 teachers were enrolled. The teachers came from a range of schools throughout New Zealand (city, rural, state, and independent) and were teaching full-time as well as studying on the programme. Although none of the teachers had a formal qualification in language teaching, they were all teaching foreign languages to learners aged 10-14 (Years 7-10). The majority of the teachers were teaching European languages (21 French, 21 Spanish and 5 German) with 5 teaching Chinese and 4 teaching Japanese (Thomson, 2008). The Language Study component of the programme was compulsory for all teachers who did not have advanced language proficiency, with the requirement that they study the target teaching language for a minimum of twelve weeks. Where possible, teachers were also encouraged to sit an internationally recognised language examination (French DELF, Spanish DELE, Chinese Proficiency Test, Japanese Language Proficiency Test, and Start Deutsch or Zertificat Deutsch. Twenty two of the 50 teachers who completed the TPDL course sat a relevant language examination and at least 19 of these passed (Thomson, 2009). The larger study involved three surveys of participants $(n=25)$. As well, there were seven volunteer case study teachers who, over the course of the year, were interviewed three times by the researchers using semi-structured interviews. The case study teachers were also observed three times teaching in their own classrooms, with researchers recording the observation through handwritten field notes. 
An area of interest that emerged from this larger study was one aspect of teachers' subject knowledge, namely their target language proficiency. In this paper we look at relevant data mainly from observations and interviews of the seven case study teachers, supported by data from surveys of the larger cohort, to explore the issues and impact of teachers' TL proficiency on their classroom practice. Table 1 provides background information about the language and level these teachers taught, their perceived level of TL proficiency and the length of time they studied the TL and whether they sat an international exam. It also includes teachers' level of confidence in using the TL with their learners at the start and end of the course.

\begin{tabular}{|c|c|c|c|c|c|c|c|}
\hline Teacher & Susan & Brenda & Debra & Carol & Flora & Gill & Karen \\
\hline Teachers' TL & Spanish & French & Spanish & Japanese & French & French & German \\
\hline $\begin{array}{l}\text { Previous TL } \\
\text { learning }\end{array}$ & $\begin{array}{l}\text { Night } \\
\text { school }\end{array}$ & $\begin{array}{l}\text { High } \\
\text { school }\end{array}$ & $\begin{array}{l}\text { Night } \\
\text { school }\end{array}$ & $\begin{array}{l}\text { High } \\
\text { school }\end{array}$ & $\begin{array}{l}\text { High } \\
\text { school }\end{array}$ & $\begin{array}{l}\text { No formal } \\
\text { study }\end{array}$ & Tertiary \\
\hline $\begin{array}{l}\text { Perception of } \\
\text { own TL } \\
\text { proficiency : } \\
\text { Start of TPDL } \\
\text { End of TPDL }\end{array}$ & $\begin{array}{l}\text { Beg } \\
\text { Beg/Elem }\end{array}$ & $\begin{array}{l}\text { Elem } \\
\text { Int }\end{array}$ & $\begin{array}{l}\text { Elem } \\
\text { Elem }\end{array}$ & $\begin{array}{l}\text { Elem } \\
\text { Elem }\end{array}$ & $\begin{array}{l}\text { Beg } \\
\text { Int }\end{array}$ & $\begin{array}{l}\text { Bilingual } \\
\text { Int }\end{array}$ & $\begin{array}{l}\text { Adv } \\
\text { Adv }\end{array}$ \\
\hline $\begin{array}{l}\text { Teachers' } \\
\text { length of TL } \\
\text { study on } \\
\text { course: } \\
\text { Exam sat } \\
\end{array}$ & $\begin{array}{l}1 \text { term } \\
\text { no exam }\end{array}$ & $\begin{array}{l}3 \text { terms } \\
\text { DELF B1 }\end{array}$ & $\begin{array}{l}2 \text { terms } \\
\text { no exam }\end{array}$ & $\begin{array}{l}1 \text { term } \\
\text { no exam }\end{array}$ & $\begin{array}{l}4 \text { terms } \\
\text { DELF A1 }\end{array}$ & $\begin{array}{l}1 \text { term } \\
\text { DELF B1 }\end{array}$ & $\begin{array}{l}\text { no study } \\
\text { no exam }\end{array}$ \\
\hline $\begin{array}{l}\text { Confidence in } \\
\text { using TL with } \\
\text { learners: } \\
\text { Start of TPDL } \\
\text { End of TPDL }\end{array}$ & $\begin{array}{l}\text { Conf } \\
\text { Conf }\end{array}$ & $\begin{array}{l}\text { Conf } \\
\text { Very conf }\end{array}$ & $\begin{array}{l}\text { Conf } \\
\text { Very conf }\end{array}$ & $\begin{array}{l}\text { Conf } \\
\text { Conf }\end{array}$ & $\begin{array}{l}\text { Very conf } \\
\text { Very conf }\end{array}$ & $\begin{array}{l}\text { Very conf } \\
\text { Very conf }\end{array}$ & $\begin{array}{l}\text { Very conf } \\
\text { Very conf }\end{array}$ \\
\hline $\begin{array}{l}\text { Student Class } \\
\text { level }\end{array}$ & (Yr7) & (Yr8) & (Yr5) & (Yr7/8) & (Yr 8) & (Yr 9) & (Yr 9) \\
\hline $\begin{array}{l}\text { Student TL } \\
\text { level }\end{array}$ & 1st year & 1st year & 1st year & 1st year & 1st year & 1st year & $\begin{array}{l}\text { 1st \& 2nd } \\
\text { yr }\end{array}$ \\
\hline
\end{tabular}

Key:

$\mathrm{TL}=$ Target Language $\quad \mathrm{Yr}=$ Year $\quad$ Beg $=$ beginner $\quad$ Elem $=$ elementary $\quad$ Int $=$ Intermediate Adv $=$ Advanced $\quad$ Conf $=$ confident

Names have been altered to preserve teacher anonymity

Table 1: Case study teachers’ background

The case study teachers taught a range of languages: French (3), Spanish (2) German (1) Japanese (1). Five were teaching learners aged 11-12 at intermediate schools where learners had one language lesson a week, while two were teaching beginner classes at high school level to 13 year olds with three periods of language learning each week.

It is difficult to have an objective measure of the teachers' proficiency in their target teaching language. As discussed by Lantolf and Frawley (1988) proficiency by nature is difficult to define as it is an open system and thus difficult to measure. The teachers were 
teaching different languages (European and Asian) and in addition, they came with widely varying target language learning experiences and qualifications that were difficult to compare. Background ranged from tertiary qualifications (1 teacher) to high school instruction (3 teachers), night school study (2 teachers) and no formal study (1 teacher). The latter teacher was in fact fluent in the TL through in-country living experience. To assist in building a picture of the teachers' language proficiency we asked them to rate their proficiency on a scale of 1-5 (beginners - bilingual). Reference to teachers' TL proficiency in this article thus refers to their perceived level rather than any external measure.

The case teachers' perception of their own target language proficiency at the start of the course ranged from beginners (2), to elementary (3) and advanced (2). At the end of the course, all but one had completed some language study, and there was a shift in their perceived level of proficiency, with 3 describing themselves as elementary, 3 at intermediate and 1 at advanced. One teacher, a non-native speaker of French,who had described herself bilingual at the beginning of the course discovered after sitting the DELF B1 exam that although she received $86 \%$ overall, and $100 \%$ in listening and speaking, her written score was lower. She thus re-graded her proficiency level downwards (Interview 2). However we still placed her overall language proficiency at an advanced level due to our observation of her proficient oral skills and written skills that were accurate in the classroom. Overall, the upward movement in perception of TL level reported by the case study teachers also reflects the survey results in the larger study cohort where there was a clear increase in reported TL proficiency from elementary to intermediate level.

As mentioned earlier, Murdoch (1994:254) notes that language proficiency is at the heart of professional confidence for the non-native teacher. Interestingly, the case study teachers, irrespective of their TL proficiency, all indicated at the start of the course that they felt 'confident' or 'very confident' about using the TL in the class. As could be expected, those teachers lacking in confidence would have been unlikely to volunteer to take part in a study that was beyond the requirements of their professional development course and in addition to their full-time teaching load. When questioned at the end of the course, all case study teachers indicated they were 'confident' or 'very confident' in using the TL in the class, a finding similar to survey three in the larger cohort where all but 2 of the 24 teachers said they were 'confident' or 'very confident.' Two of the case study teachers who ranked themselves at elementary/intermediate on the 5 point language proficiency scale indicated they had developed further confidence in using the TL with their learners.

In summary, a range of languages was taught by the case study teachers to different levels of learners. Two teachers had a high self-perceived level of TL proficiency, five had more limited subject knowledge and all teachers indicated they were confident throughout the study in using the TL with their learners.

This paper reports on the extent of the difference in the classroom practices of teachers with varying levels of subject knowledge. To investigate the relationship between teachers' subject knowledge and their classroom practice, we analysed data from the seven 
case study teachers' interviews and observations against aspects of teaching drawn from Farrell and Richards (2007:57) and supported by others (Krashen 1982; McNamara 1991; Chaudron 1998; Schulz 1999; Borg 2001; Naserdeen 2001, Tsui, 2003; Ellis 2005; Scrivener 2005; Kim and Elder 2008; Edge and Garton 2009):

1) exploitation of target language resources

2) provision of appropriate language models

3) provision of corrective feedback

4) use of the TL to manage the class

5) provision of accurate explanations

6) provision of rich language input

7) ability to improvise

\section{Results}

Table 2 shows the results of our analysis of case study observation data using the listed aspects of teaching. It is clear from the table that the two teachers with advanced TL proficiency were observed operating in all seven aspects of teaching. The remaining five, with limited proficiency in the language they were teaching, attempted the first four aspects of teaching to varying degrees. However, they were unable to provide rich language input at a natural pace and showed little ability to respond to questions about the target language or culture. 


\begin{tabular}{|c|c|c|c|c|c|c|c|}
\hline \multirow[b]{2}{*}{$\begin{array}{l}\text { Aspects of teaching } \\
\text { (Adapted from Farrell \& Richards, 2007) }\end{array}$} & \multicolumn{7}{|c|}{ Teacher, their perception of Target Language (TL) proficiency and observed aspects of teaching } \\
\hline & $\begin{array}{l}\text { Susan } \\
\text { (Beg-Elem) }\end{array}$ & $\begin{array}{l}\text { Brenda } \\
\text { (Elem-Int) }\end{array}$ & $\begin{array}{l}\text { Debra } \\
\text { (Elem-Elem) }\end{array}$ & $\begin{array}{l}\text { Carol } \\
\text { (Elem-Elem) }\end{array}$ & $\begin{array}{l}\text { Flora } \\
\text { (Beg-Int) }\end{array}$ & $\begin{array}{l}\text { Gill } \\
\text { (Adv-Int) }\end{array}$ & $\begin{array}{l}\text { Karen } \\
\text { (Adv-Adv) }\end{array}$ \\
\hline $\begin{array}{l}\text { 1. Accessed and exploited TL resources, (eg. } \\
\text { textbook, internet, newspapers) }\end{array}$ & $\sqrt{\sqrt{ }}$ & $\sqrt{\sqrt{ }} \sqrt{2}$ & $\sqrt{\sqrt{ }}$ & $\sqrt{\sqrt{ }}$ & $\sqrt{\sqrt{ }}$ & $\sqrt{\sqrt{ }}$ & $\sqrt{\sqrt{ }} \sqrt{ }$ \\
\hline $\begin{array}{l}\text { 2. Provided appropriate TL language models of } \\
\text { vocabulary, structures, social language }\end{array}$ & $\sqrt{\sqrt{ }}$ & $\sqrt{ } \sqrt{ }$ & $\sqrt{\sqrt{ }}$ & $\sqrt{ }$ & $\sqrt{\sqrt{ }}$ & $\sqrt{\sqrt{ }}$ & $\sqrt{\sqrt{ }} \sqrt{2}$ \\
\hline $\begin{array}{l}\text { 3. Provided appropriate corrective feedback on } \\
\text { learner error. }\end{array}$ & $\sqrt{\sqrt{ }} \sqrt{ }$ & $\sqrt{\sqrt{ }}$ & $\sqrt{\sqrt{ }} \sqrt{ }$ & $\sqrt{ }$ & $\sqrt{ }$ & $\sqrt{\sqrt{ }} \sqrt{ }$ & $\sqrt{\sqrt{ }} \sqrt{ }$ \\
\hline $\begin{array}{l}\text { 4. Used appropriate TL classroom language to } \\
\text { manage class }\end{array}$ & $\sqrt{ }$ & $\sqrt{ }$ & $\sqrt{ } \sqrt{ }$ & $\sqrt{ }$ & $\sqrt{ } \sqrt{ }$ & $\sqrt{ } \sqrt{ }$ & $\sqrt{ } \sqrt{ }$ \\
\hline $\begin{array}{l}\text { 5. Provided accurate meaningful explanations of } \\
\text { vocab \& structures }\end{array}$ & $\sqrt{ }$ & & & $\sqrt{ }$ & $\sqrt{ } \sqrt{ }$ & $\sqrt{ } \sqrt{ }$ & $\sqrt{ } \sqrt{ } \sqrt{ }$ \\
\hline $\begin{array}{l}\text { 6. Provided rich language learning input: } \\
\text { T use of TL: natural pace; repetition of functional } \\
\text { language; well graded language; longer utterances, } \\
\text { complex sentences; cultural anecdotes }\end{array}$ & & & & & & $\sqrt{ } \sqrt{ }$ & $\sqrt{ } \sqrt{ }$ \\
\hline $\begin{array}{l}\text { 7. Improvised within lesson (able to respond to } \\
\text { questions about the TL or about the culture). }\end{array}$ & $\sqrt{ }$ & & & $\sqrt{ }$ & & $\sqrt{\sqrt{ }}$ & $\sqrt{\sqrt{ }}$ \\
\hline
\end{tabular}

Table 2: Subject knowledge and observed aspects of teaching 
This section elaborates on Table 2 and gives examples.

\section{Exploitation of target language resources}

Teachers' access to and use of target language resources, such as textbook, magazine and internet is the first area considered. All seven case study teachers had access to a textbook and in some cases an accompanying DVD. Rather than strictly using the textbook as a course book to be followed each lesson, most teachers in interview mentioned using it as a resource, preparing worksheets from it as appropriate. Some textbooks included authentic material such as one of Grimms' fairy tales which the teacher used to activate students' schema about fairy tales they were familiar with. In addition, teachers supplemented their lessons by accessing other language learning support materials such as posters, vocabulary cards and teacherprepared wall charts of formulaic language chunks for students to refer to. A number of teachers were observed teaching songs in the TL as part of their lessons. One teacher with an advanced level of TL proficiency was able to exploit authentic material on the internet, asking learners to download the weather forecast as a way to introduce terminology in German to talk about the weather.

\section{Provision of appropriate models}

This category relates to the teachers' provision of appropriate (i.e. accurate and useful) models of target language for their students. It includes the presentation and use of TL vocabulary, structures, social language and formulaic expressions such as Have a nice weekend, What does this mean? When they had planned their teaching, most teachers could provide appropriate and useful models of accurate TL for their learners. All teachers taught social language and formulaic expressions, such as What's the date today? What's your name? Can I get a drink? I like/don't like. They also taught key basic vocabulary such as numbers, colours, and every day topics (eg. food, family members and items of clothing). One teacher of Spanish was observed grouping her learners to play the card game Vaya Pez.....(Go Fish). She gave her beginner learners a prepared list of useful phrases to use during the card game, and learners played the game, using TL for phrases such as, Whose turn is it? It's my turn, Pick up the cards, Let's play again and Don't cheat! One teacher, although she provided accurate models of the target language, did not always present language that was useful. For example, in her enthusiasm to arrange an interactive task, this teacher had students in a mingle activity practising the TL phrase for Are you in my family? a phrase which would clearly have no application beyond the classroom exercise.

\section{Provision of corrective feedback}

In this aspect of managing teaching we consider the teachers' provision of appropriate corrective feedback on learner error and the type of feedback they gave. Teachers were all observed providing corrective feedback on learner error, although one teacher who had limited language provided feedback that was not accurate. Two teachers were observed correcting learners' use of masculine and feminine forms. All teachers were observed correcting learners' pronunciation. One teacher of Spanish helped students with 
pronunciation by breaking down neocelandessa/neocelandes (New Zealander) into syllables. Others provided an accurate model of word in the TL and asked students to listen and repeat, eg. écoutez, répétez: histoire (listen, repeat: history). One of the two teachers with an advanced level of TL proficiency corrected her French learners' pronunciation by asking them questions to help them notice the difference between the correct and incorrect form of comment so learners were able to produce the correct form.

T: Comment sont-ils? (How are they?) Do I say comment?

SS: No.

T: How do I say it?

SS: (with correct pronunciation) Comment.

The other teacher with an advanced level of proficiency asked students to recall how to produce words beginning with ' $w$ ' in German. Students responded with /v/ and the teacher then went on to provide them with a written record of the correct pronunciation.

\section{Use of TL to manage the class}

The fourth aspect concerns the teachers' use of the target language when managing the class, for example to put learners into groups, start the lesson, control activities, discipline students and praise learners. With regard to the cohort of teachers in the wider study, Thomson (2009: Appendix 27) records that by the end of the course, the majority of teachers observed (43 of the 47) were either meeting or exceeding the progress standards for teacher TL use in the classroom, i.e. they were 'making significant use of the TL for social goals, classroom management and instruction' (Appendix 13). Observations of the case study teachers indicated a range in the amount of TL teachers used to manage the class. One teacher was observed counting in the TL to get the attention of the class. However, she admitted in interview that she did not feel proficient enough in the TL to use it for keeping full control of the class. This was confirmed in observation when she used sentences with a mixture of English and TL such as 'Get your hon (book) out.' All the remaining teachers were observed managing the class with a range of TL phrases such as Be quiet, Are you ready, Begin. In addition, all teachers encouraged learners by using language such as Well done, Good, Excellent. Three teachers when giving complex instructions in the TL commented in interview that they sometimes chose to use both English and the TL in the same sentence to ensure students understood. Eg. 'Regardez, s'il vous plait (Look, please). Now we're going to count to 30 all together.'

\section{Provision of meaningful explanations}

The provision of accurate and meaningful explanations includes elaborating on meaning and usage of key vocabulary items and language structures. Two of the seven teachers were not observed elaborating on vocabulary or language structures at all. However, three teachers attempted to provide some meaningful explanations of basic TL language features, using the 
TL and English. For example, one teacher who described herself at an elementary level of TL proficiency, drew learners' attention through translation to the difference in meaning between soy de mexico (I'm from Mexico) and soy mexicano (I'm Mexican). The two teachers who were at an advanced level of TL proficiency provided useful, accurate and meaningful explanations throughout their observed lessons. For example, one teacher skilfully asked questions to elicit how French speakers drop the 'e' on je when the following verb starts with a vowel.

Teacher pointed to sentence on board, j'adore le chat and reminded students of two rules previously studied.

T: deuxieme rule? (second rule?)

S: Drop 'e' on le.

T: On le?

S (self-correcting): On je.

T: Why?

S: Because you can't have two vowels together.

As well, this teacher was observed eliciting and explaining a range of language points such as verb conjugations and plural forms, always codeswitching with English. The other teacher who had an advanced level of TL proficiency was also observed explaining or eliciting rules for language formations. For example she code-switched to remind a student who queried the use of das and die that words ending in 'e' often take the article die. She also clarified other vocabulary items such as gehen (to go) and fahren (to go in a vehicle), and essen (to eat) and fressen (to eat like an animal). It is important to note that the researchers felt the two proficient teachers were capable of scaffolding the learning fully in the TL. However the level of the language learners was such that the teachers felt they needed to code-switch. As one teacher commented in the first interview, 'I use English and German because I want to make sure the learners get the point.' In other aspects of their classroom practice, such as managing the class, giving instructions and using social language, these two teachers were observed using the TL fluently and without the use of English. In their first interviews, one teacher said that she had 'no qualms' about using the TL in the classroom, and the other commented that she was 'pushing the immersion experience, hardly uttering a word of English.’

These two teachers with advanced language proficiency, and one other teacher (who rated herself at 'intermediate' level by the end of the course) consistently provided meaningful explanations. However, the remaining four teachers were either not observed doing this, or did so only occasionally.

\section{Provision of rich language input}


This category refers to the teachers' ability to use the TL at an appropriate level for their learners. They need to be able to speak the language at a natural pace, vary structures used for functional language and use longer utterances and more complex sentences with advanced learners. In addition, the provision of rich language input includes the teachers' ability to draw on their understanding of the target language culture to extend student learning.

Only two teachers were observed providing rich language learning input through the use of natural extended TL delivery and cultural anecdotes. Both these teachers had advanced TL proficiency at the start of the course. A useful example of rich language for learners was when one teacher who was monitoring two students used their names and exposed them to every day TL with longer utterances, delivered at a natural pace. Ah, c'est jolie, ça - tu as fini, Jane. Mais Susie doit finir. C'est bon, ça (Oh, that's lovely that is, - you've finished, Jane. But Susie has to finish. That's really good). She also exposed them to a new structure when encouraging them to complete their work. Rather than saying dépêchez-vous - 5 minutes (Hurry up - 5 minutes), she was able to deliver more colloquial structures, Allez, dépêchezvous. Il ne reste que 5 minutes. Another example of exposure to extended delivery was when, in closing the task, the teacher said, On arrête là. Posez les stylos. Fermez les livres (We'll stop there. Put your pens down. Close your books). When giving instructions, she repeated them three times to give learners the chance to understand and respond appropriately. The other teacher with an advanced level of TL proficiency also used longer utterances and complex sentences when giving instructions. It was also noted that both teachers provided cultural anecdotes (using code-switching) during their lessons, making them more memorable. For example, one teacher used her knowledge of Christmas markets in Europe to make a link between the classroom and the TL culture, explaining in English that they could buy Printen (gingerbread hearts) in the market, and answering student questions about how big the Printen were. She then moved on to asking students Wie heisst sweets auf Deutsch? (What are sweets in German?) and a student gave the answer die Bonbons.

\section{Ability to improvise}

Improvising in the language classroom is demonstrated through teachers' ability to seize the teaching moment and respond spontaneously to learners' questions about the target language and culture. Three teachers, who had low TL proficiency, did not demonstrate an ability to improvise and respond fully to learner questions and move away from their planned delivery. For example, when asked questions by students such as 'What's the word for....in the TL?' these teachers responded by directing learners (in English) to the dictionary or to the Language Tools on the interactive whiteboard. Two teachers with low TL proficiency however were occasionally able to deviate from their lesson plan to respond spontaneously to learners' queries. The following dialogue is an example of how one of these teachers responded to students' questions about age.

T: (writing on the whiteboard) Oh, since it's come up: Cuántos años tienes.

T: Listen and repeat: Cuántos años tienes. 
SS: Cuántos años tienes.

T: So the translation is: How many years have you got?

SS: How old are you, Miss?

T: Tengo 29 años. Mi cumpleaños es en septiembre.

SS: Say that again please.

T: Tengo 29 años. Mi cumpleaños es en septiembre.

SS: How do you say 'When's your birthday?'

T: Asking about birthdays is different. One thing at a time!

SS: How do you sing Happy Birthday in Spanish?

T: That's a good idea. We'll do that later.

At the end of the lesson, the teacher wrote the words for Happy Birthday in Spanish on the board, and the class sang it twice. The students were fully engaged, and the teacher had sufficient TL and confidence to be able to answer a series of questions, albeit with codeswitching, and capture the teaching and learning moment on this occasion. The two teachers with advanced level of TL proficiency also demonstrated the ability to capture the teaching moment to expand on learners' knowledge. They were consistently observed spontaneously responding (in TL with some use of English) to student questions about the TL or about the culture throughout the lessons.

\section{Discussion}

The evidence indicates that, with respect to teachers' levels of TL proficiency, there are differences in the number of aspects of teaching that teachers are able to manage. There is also variance in their level of effectiveness in managing these aspects. All teachers, regardless of TL proficiency could manage the first four aspects of language teaching (exploit target language resources, provide some appropriate language models, offer corrective feedback, and use the TL to manage the class).

The teachers with lower levels of TL proficiency were able to correct learner grammar errors in structures they were teaching. However, they were more limited in other aspects of corrective feedback, for example being unable to provide correct pronunciation of new words learners found in the dictionary. Most teachers identified basic pronunciation errors in familiar language, mainly using 'listen and repeat' corrective techniques. The two more fluent teachers demonstrated more language awareness by augmenting 'listen and repeat' through questioning students, thereby leading them to a greater understanding of the correct form of pronunciation. Teachers with less TL proficiency did not consistently provide meaningful explanations of vocabulary or grammar to students in the observed lessons. 
Only the two teachers with a high level of TL proficiency demonstrated management of all seven aspects of language teaching. A noticeable finding was that it was mainly these teachers who consistently provided rich target language input and responded spontaneously to their learners either in the TL or in English as appropriate. Learners in the classes taught by these two teachers were exposed to a wide range of language structures and vocabulary. In classroom management, rather than using just fixed phrases for grouping, disciplining and praising learners, these teachers used a wide range of language exponents in the TL for the same function. They also frequently repeated TL instructions, giving the students plenty of time to understand and respond. It must be noted however that these two teachers taught in high school where learners had more hours of language learning per week. Thus there were more opportunities to use extended utterances and provide richer language input as the class made progress, in comparison with the other five lower level proficiency teachers who were working in intermediate schools. It was also a teacher with advanced knowledge of the language who was observed accessing the internet for authentic, current materials for classroom use, which helped make her lesson motivating for students. This application helped bridge the gap between the classroom and the TL community and the students' own lives. Both this teacher and the other fluent teacher had had in-country language learning experience. These two teachers were observed using their knowledge of the culture to contextualise the language, enhance their lessons, and provide some opportunities for learners to develop intercultural competence (Richards, Conway, Roskvist \& Harvey 2010:11).

The two teachers who could manage all seven aspects of language teaching demonstrated effective language teaching pedagogy. This may be because they were less concerned with developing their TL proficiency and so could focus on language teaching pedagogy taught during the course. One teacher in interview at the beginning of the TPDL programme commented, 'The language study part of the TPDL programme is unnecessary for me as my TL is high, so now I can focus on the methodology' (Karen, Interview one).

\section{Conclusion}

In the absence of sufficient numbers of qualified language teachers, language teacher professional development can be offered to generalist teachers who have an interest in language learning but minimal language competence (East 2007:38). Our evidence indicates that teachers with low level TL proficiency were able carry out some aspects of effective language teaching. However, teachers need to have an advanced level of TL proficiency so they can also provide meaningful explanations, rich language input for learners and respond spontaneously and knowledgeably to their learners' questions on language and culture. Teachers also need an advanced level of proficiency in order to take learners beyond the beginner level of study. This is particularly important in the high school context where learners have the opportunity to progress through five years of language instruction.

In situations where there is a shortage of language teachers, policy makers may choose to offer professional development to trained generalist teachers with an interest in the language, but not necessarily advanced proficiency in the language. In these contexts there 
needs to be a strong focus on developing teachers' language proficiency to a high level so they are fully able to manage the seven key aspects of language teaching. Teachers' language development needs to take place on the course, as well as beyond the course until an appropriate level of proficiency in the target language is attained. On course development needs to be tailored to the needs of the teacher participants, i.e. rather than learning the language for a minimum length of time, teachers need to be learning the language until they have a high level of proficiency. As this level may not be reached by teachers during the course, facility needs to be available for them to continue to study the TL post course. In some cases, this may be through study abroad awards. Alternatively support may come from schools in a range of ways, such as financial, time release from teaching, and encouragement to sit language exams.

In the New Zealand context, the TPDL programme is just a one year programme for teachers. However, the programme director encourages teachers to pursue further language study beyond the course, for example in supporting course graduates to sit further language exams. In addition International Languages Exchanges and Pathways (ILEP), on behalf of the Ministry of Education, has recently established a coherent five stage professional pathway with the goal of consolidating the professional learning and development of language teachers, including the development of language proficiency (ILEP, 2011).

Commitment to building teachers' language proficiency is a long-term investment, as it is well-known that learning language is a developmental process (Crabbe 2005:2) and becoming proficient in another language takes time. Without this investment in their subject knowledge, teachers with low level TL proficiency would only be able to provide beginner level students with a limited introduction to the foreign language. 


\section{References}

ACTFL. 2002. ACTFL/NCATE Program standards for the preparation of foreign language. Retrieved June 30, 2011 from www.actfl.org.

Bachman, L. F. 1990. Fundamental consideration in language testing. Oxford, England: Oxford University Press.

Borg, S. 2001. Self-perception and practice in teaching grammar. ELT Journal 55, no.1: 21 29.

Chaudron, C. 1998. Second language classrooms: research on teaching and learning. Cambridge, England: Cambridge University Press.

Crabbe, D. 2005. The essence of learning second languages in the New Zealand school context. The New Zealand Curriculum Online. Retrieved June 30, 2009 from http://nzcurriculum.tki.org.nz/Curriculum-project-archives/Consultation-andfeedback/Reports-and-analyses

Crichton, H. \& Templeton, B. 2010. Curriculum for Excellence: the way forward for primary languages in Scotland? The Language Learning Journal 38, no. 2: 139-147. doi:10.1080/09571731003790391

East, M. 2007. Learning languages in New Zealand: how successful can it be? In The New Zealand Language Teacher 33, November: 7-9.

Edge, J., \& Garton, S. 2009. From experience to knowledge in ELT. Oxford, England: Oxford University Press.

Education Review Office. 2009. Readiness to implement the New Zealand Curriculum. Wellington, New Zealand: Education Review Office. Retrieved June 30, 2009, from http://ero.govt.nz.

Ellis, R. 2005. Instructed second language acquisition: A literature review. Wellington: Ministry of Education. http://www.educationcounts.govt.nz/publications/schooling/5163

Farrell, T.S. \& Richards, J. 2007. Teachers' language proficiency. In T. S. Farrell (Ed.), Reflective language teaching: from research to practice (pp.55-66). London, England: Continuum.

Gibbs, R. \& Holt, R. 2003. The teaching of international languages in New Zealand schools in Years 7 and 8: an evaluation study. Report to the Ministry of Education. Auckland: Auckland University of Technology.

Guthrie, J. 2005. Have you got a Japanese teacher up your sleeve? New Zealand principals' perceptions of language teacher supply. New Zealand Studies in Applied Linguistics 11, no. 2: 43-58. 
Harvey, S., Conway, C., Richards, H., \& Roskvist, A. 2009. Evaluation of teacher professional development languages (in Years 7-10) and the impact on language learning opportunities and outcomes for students. Report to the Ministry of Education. Auckland: Auckland University of Technology. http://www.educationcounts.govt.nz/publications/schooling/76014/76092

ILEP 2011. Professional pathways for schools and teachers for learning languages. http://www.ilep.ac.nz/PathwaysforLearningLanguages.aspx

Kim, S. \& Elder, C. 2008. Target language use in foreign language classrooms: practices and perceptions of native speaker teachers. Language, Culture and Curriculum 21 no. 2: 167-185. doi:10.1080/07908310802287574

Lantolf, J. \& Frawley, W. 1988. Proficiency: Understanding the construct. Studies in Second Language Acquisition, 10, no.2: 181-195.

Lightbown, P. \& Spada, N. 1999. How languages are learned. ( ${ }^{\text {nd }}$ ed.). Oxford, England: Oxford University Press.

McNamara, D. 1991. Subject knowledge and its application: oroblems and possibilities for teacher educators. Journal of Education for Teaching, 17, no. 2: 113-128.

Ministry of Education. n.d. Statement of intent 2007 - 2012. Wellington: Ministry of Education. Retrieved October 24, 2008, from http://www.minedu.govt.nz/theMinistry/PublicationsAndResources/StatementOfInten t/SOI2007.aspx

Ministry of Education 2007. The New Zealand Curriculum. Wellington, New Zealand: Learning Media.

Murdoch, G. 1994. Language development provision in teacher training curricula. ELT Journal 48, no.3: 253-265.

Naserdeen, D. 2001. Second language study in elementary schools. Multicultural Education 8, no.3: 21-23.

Pachler, N., Evans, M. \& Lawes, S. 2007. Modern foreign languages: Teaching school subjects 11-19. Oxon, England: Routledge Richards, H., Conway, C., Roskvist, A. \& Harvey, S. 2010. Intercultural Language Learning (IcLL): awareness and practice of in-service language teachers on a professional development programme. New Zealand Studies in Applied Linguistics 16, no.1: 1-15.

Schulz, R. 1999. Foreign language instruction and curriculum. Education Digest 64, no. 7: 29-37.

Shin, S. 2008. Preparing non-native English speaking ESL teachers. Teacher Development 12, no. 1: 57-65. doi:10.1080/13664530701827749 
Stelma, J. \& Onat-Stelma, Z. 2010. Foreign language teachers organising learning during their first year of teaching young learners. The Language Learning Journal 38, no. 2: 193-207. doi:10.1080/09571731003790490

Thomson, W. 2009. Teacher professional development languages Years 7-8: Milestone 9. The University of Auckland, Auckland: Auckland Uniservices Ltd.

Thomson, W. 2008. Teacher professional development languages Years 7-10: Milestone 5. The University of Auckland, Auckland, New Zealand: Auckland UniServices Ltd.

Tsui, S.B.M. 2003. Understanding expertise in teaching. Cambridge, England: Cambridge University Press. 